\title{
Anti-Biofilm Drug Susceptibility Testing Methods: Looking for New Strategies against Resistance Mechanism
}

\section{Juan Bueno*}

Bioprospecting Development and Consulting, Bogotá, Colombia

\begin{abstract}
Biofilm is a reservoir of drug resistant microorganisms that can increase the failure rate of anti-infective therapy and is a public health concern. Antibiofilm drug discovery is necessary for developing new drugs, biocides and wound management protocols. This makes the standardization and implementation of in vitro antibiofilm screening platforms a challenge in the search for new antibiotics, because current antimicrobials are active against planktonic bacteria and have poor diffusion across biofilm matrix. Usually, based in the research topic, the antibiofilm methods have been classified in static and flow depending of continuous supply of nutrients that affect the microbial growth, the final aim of these assays is obtain Minimal Biofilm Inhibitory Concentration (MBIC) and Minimal Biofilm Eradication Concentration (MBEC) values as efficacy parameter of the compound or procedure evaluated, but is very important correlates data from different models in order to give real results of activity. This review aims at describing the initial tools for to establishing an antibiofilm drug discovery-prospecting program.
\end{abstract}

Keywords: Antibiofilm activity; Screening methods; Biocides; Antimicrobial drugs

\section{Introduction}

Biofilms are defined as a normal pattern of microorganisms organized in microbial communities that are attached on an inert or living surface. Biofilms are embedded in a matrix containing polysaccharides, proteins, and extracellular microbial DNA [1-3]. Because provides a reservoir for microbial cells, its dispersion enhances the risk of chronic and persistent infections. It may also promote the reinfection of colonized sites [4,5]. Likewise the matrix confers a protection against biocides and drugs and have environmental promoters that induce biofilm formation and contributes to drug resistance development [6,7], therefore biofilms cause approximately 100,000 hospital deaths per year in the United States and $80 \%$ of human microbial infections [8].

Several mechanisms have been reported for increased antimicrobial resistance in biofilm structures [9]:

- Low diffusion of antibiotics across the polysaccharide matrix. By three ways, as are, increase of the transmembrane pressure drop, increase of feed channel pressure drop, and increase of transmembrane passage [10].

- Physiological changes due to slow growth rate and starvation responses (oxygen, nutrient deprivation or environmental stress).

- Phenotypic change of the cells forming the biofilm.

- Quorum-sensing.

- The expression of efflux pumps that decrease intracellular antimicrobial concentration.

- The emergence of persister cells which are multi drug-tolerant cells that have not acquired genetic resistance [11].

Similarly biofilm structure promotes the antibiotic resistance through facilitated horizontal gene transfer due to the high microbial population density. Through conjugation process that permits biofilm formation [12]. All these factors contribute to biofilm cells being 1000fold more resistant to antimicrobial agents than planktonic cells $[2,13]$.
Equally, the current treatment and control of biofilm is complicated, because antimicrobials have been developed against planktonicallygrown bacteria and microorganisms in metabolically active stage [14].

Biofilm formation, maturation and dispersion can be measured both in vitro and in vivo using antimicrobial standardized assays developed to determinate responses of bacterial population to different compounds. Because the biofilm environment can contribute to the emergence of antibiotic resistance does an urgent need to obtain new drugs and biocides that prevent or inhibit biofilm formation and have microbicidal activity on cells inhabit biofilms structure? To achieve such goal effective high throughput in vitro assays for screening potential therapeutics and control measures must be developed [15]. Therefore the aim of this paper is to review the methods currently available for such purpose, under the criteria optimization screening platforms that can be robust, reproducible and automatable greater extent and offer alternatives for cross "the valley of death" between biofilm susceptibility testing and antibiofilm drug discovery.

\section{In vitro Antibiofilms Screening Models}

In antibiofilm screening activity traditionally there has been two models of in vitro study, static and flow (Table 1). In flow methods biofilms are grown with continuous flow of fresh medium whereas static medium are only batch cultures. Static assays can be used for study to study early stages of biofilm formation [16]. On the other hand, flow cell systems that provide a constant supply of nutrients across microbial cells attached to a synthetic surface, are considered as the gold standard for assessing developmental processes associated with biofilm formation [17]. Using both types of assays one aims at

*Corresponding author: Juan Bueno, MD, MSc, Bioprospecting development and consulting, Bogotá, Colombia, Tel: 571-3108323975; E-mail: juangbueno@gmail.com

Received April 14, 2014; Accepted May 12, 2014; Published May 16, 2014

Citation: Bueno J (2014) Anti-Biofilm Drug Susceptibility Testing Methods: Looking for New Strategies against Resistance Mechanism. J Microbial Biochem Technol S3: 004. doi:10.4172/1948-5948.S3-004

Copyright: (c) 2014 Bueno J. This is an open-access article distributed under the terms of the Creative Commons Attribution License, which permits unrestricted use, distribution, and reproduction in any medium, provided the original author and source are credited 


\begin{tabular}{|c|c|c|c|c|c|c|}
\hline \multicolumn{7}{|c|}{ Antibiofilm screening assay } \\
\hline \multicolumn{3}{|c|}{ Static } & \multirow[t]{2}{*}{ Flow } & \multirow[t]{2}{*}{ Genetic } & \multirow{2}{*}{$\begin{array}{l}\text { Whole animal biofilm } \\
\text { models }\end{array}$} & \multirow{2}{*}{$\begin{array}{l}\text { Functional biofilm } \\
\text { model }\end{array}$} \\
\hline Colorimetric & Fluorometric & Magnetic & & & & \\
\hline Crystal violet & Resazurin & $\begin{array}{l}\text { Bio Film Ring } \\
\text { Test }^{T M}\end{array}$ & $\begin{array}{l}\text { Kadouri drip-fed biofilm } \\
\text { system }\end{array}$ & $\begin{array}{c}\text { Real Time Quantitative- } \\
\text { Reverse Transcription- PCR } \\
\text { (qRT-PCR) }\end{array}$ & Caenorhabditis elegans & Quorum sensing \\
\hline Safranin & SYTO-9 & & $\begin{array}{l}\text { Modified Robbins } \\
\text { Device (MRD) }\end{array}$ & $\begin{array}{l}\text { Fluorescence in situ } \\
\text { hybridization (FISH) }\end{array}$ & Galleria mellonela & $\begin{array}{l}\text { Antibiofilm detachment } \\
\text { activity }\end{array}$ \\
\hline MTT, XTT, TTC & Propidium iodide & & $\begin{array}{c}\text { Tubular Capillary } \\
\text { Electrochromatography } \\
\text { (CEC) }\end{array}$ & & & Checkerboard assay \\
\hline $\begin{array}{c}\text { Biofilm Eradication } \\
\text { Surface Test (BEST) } \\
\text { Assay }^{\mathrm{TM}}\end{array}$ & FDA/EB & & FC270 flow-cell system & & & $\begin{array}{l}\text { In vitro wound biofilm } \\
\text { model }\end{array}$ \\
\hline MBEC Assay ${ }^{\top M}$ & & & Microfluidic devices & & & Bioluminiscence \\
\hline \multicolumn{4}{|c|}{ Isothermal calorimetry* } & & & $\begin{array}{c}\text { Confocal Láser } \\
\text { Scanning Microscopy } \\
\text { (CLSM) }\end{array}$ \\
\hline \multicolumn{4}{|c|}{ Biofilm dielectric biosensor* } & & & \\
\hline
\end{tabular}

${ }^{*}$ Can be used both for static as flow biofilm studies

Table 1: Classification of antibiofilm screening assay.

determining the Minimal Biofilm Inhibitory Concentration (MBIC) and Minimal Biofilm Eradication Concentration (MBEC) as in vitro static parameters of drug efficacy. On the other hand, dynamic interaction between antimicrobials and biofilms can be determinated by time-kill curves which measure antibiotic action in function of the concentration and time [18]. Other techniques have been developed in the interest of providing as much information on the interaction between different substances to evaluate and biofilms, as molecular targets, biofilm thickness and inhibition of biofilm factors that contribute to drug resistance in different stages (Table 1).

\section{Static Antibiofilm Screening Assay}

\section{Colorimetric}

The quantitative assay methods for anti-biofilm activity based in colorimetric methodologies are similar to the microbroth dilution assay described in the Clinical Laboratory and Standards Institute (CLSI) document M7-A7. In addition, some assays can be adapted for high-throughput screening [19]. The conventional method is staining with crystal violet $(\mathrm{CV})$, followed by washing, CV extraction, and measurement of CV-specific absorption at $590 \mathrm{~nm}$. Although this essay is the most easy to perform, CV is susceptible to inaccuracies, because it is not able to classify between living or dead organisms within the biofilm. However the CV assay can be complemented by conventional plate counts to monitor the decreasing numbers of detected by counting colony forming units (CFU) from re-suspended biofilms. However, this technique is slow and error-prone due to the possibility of incomplete removal from the surface or imperfect resuspension before plating and not possesses the sensitivity to monitor primary adhesion events $[20,21]$. Another commonly used is safranin staining that predominantly detects extracellular substances as Exopolysaccharide (EPS) that is present in biofilm matrix in a large amount and is composed of sugar polymers, safranin is commonly used to quantify biofilm mass and can be evaluated using light microscopy at a magnification of $\times 140$, the relative amount of biofilm can be quantified by an optical density (OD) measurement at $490 \mathrm{~nm}$ [22-24]. For quantification of bacterial viability in static biofilm, metabolic assays using tetrazolium salt derivatives such as 3-(4,5-dimethylthiazol-2-yl)- 2,5-diphenyltetrazolium bromide (MTT, closely related tetrazolium dyes including XTT and TTC) are excellent candidates. These assays are based on the detection of metabolic products produced by microbial cells and have the advantage of being able to automation in a microplate reader at $560 \mathrm{~nm}$ (absorbance of formazan produced by tetrazolium salts metabolism) and at $700 \mathrm{~nm}$ (absorbance for the tetrazolium salt) without sample handling by not requiring removal of the biofilm, only the extraction of the dye $[25,26]$. However, limitations as susceptibility to respiration rate of bacteria and time growth and biofilm thickness should be considered, because attached cells do not have the same metabolic activity as planktonic cells. In addition, a decrease in the vital dye reduction has been described in the presence of antibacterial compounds, reducing then the reproducibility of this method in anti-biofilm drug discovery $[27,28]$.

In the same way using metabolic assays in screening platforms were developed Biofilm Eradication Surface Test (BEST) Assay ${ }^{\mathrm{TM}}$ and MBEC Assay $^{\mathrm{TM}}$. MBEC Assay ${ }^{\mathrm{TM}}$ uses the 96-well plate format for evaluate the antibiotic susceptibility of microbial biofilms and has been used to evaluate different clinically relevant microorganisms as, Pseudomona spp., Staphylococcus spp., and Mycobacterium spp. This system has also been proven in a number of studies including the evaluation of biocides used for food and decontamination of surfaces. The MBEC is determined from the biofilm growing on the special 96-peg lid and suspend into the wells of the microtitre plate. MBIC and MBEC values derived from the planktonic and attached organisms in the plate wells have been validated against CLSI standards $[29,30]$.

Equally, Biofilm Eradication Surface Test (BEST) Assay ${ }^{\mathrm{TM}}$ have been used for to evaluate biofilm removal in different surfaces, this system utilizes a versatile, multi-well plate technology that allows biofilm growth on a wide variety of surface materials in combination with metabolic dyes or CFU counting. The biofilms attached on different surfaces cultured on the BEST ${ }^{\mathrm{TM}}$ can be transferred to multiwell plates for disinfection and drug discovery tests [31].

\section{Fluorometric}

Spectrofluorometric biofilm assay have shown be more sensitive and specific than the colorimetric method [32]. Fluorometric assays 
give more precise measurements, do not involve cell lysis, and are susceptible of being used with functional assays in fluorescence and/ or absorbance screening platforms [33]. Among them resazurin (7-hydroxy-3H-phenoxazin-3-one-10-oxide) a blue redox dye that is reduced by metabolically active cells to the pink fluorescent product resorufin, fluorescence signals are measured at an excitation wavelength at $530-560 \mathrm{~nm}$ and an emission wavelength at $590 \mathrm{~nm}$ providing an automatable antibiofilm screening protocol. But, it is important take into account a number of factors that influence the results of fluorescent signal. For example, metabolic differences between microorganisms, which makes it necessary to optimize dye incubation time. Similarly fluorescent signals can be detected in high bacterial concentrations $\left(10^{7}\right.$ $\mathrm{CFU} / \mathrm{ml}$ ), for that reason various quantification methods should be performed in low biofilm concentrations. Finally it is important to use calibration curves with biofilms for develop analysis between measured resazurin fluorescent signal and anti-biofilm screening assays [34].

Other methods implemented in high content screening (HCS) to measure bacterial adhesion as well as biofilm formation and removal are using fluorescent dye as SYTO-9 and propidium iodide, SYTO-9 green fluorescent nucleic acid stain labels all cells whether living or dead, while the red fluorescent nucleic acid stain, propidium iodide, enters only cells with damaged membranes. This HCS assay quantifies total adhered cells as well as allows measure viability of adhered cells and biofilm alteration by treatment with antimicrobial compounds and is compatible with functional assays [21,35]. Likewise are present in commercial platforms for viability cell as LIVE/DEAD ${ }^{\circledast}$ BacLight $^{\mathrm{TM}}$ Bacterial Viability Kit [36]. Due to method limitations, such as the influence in the results of interaction between total bacterial counts and the quantity of the stain used, an alternative may be to use FDA/EB (Fluorescein Diacetate/Ethidium Bromide) stain that does not present concentration dependence in the reaction [37]. Although mutagenicity of EB remains controversial, FDA/EB fluorescence assay seems to be one of the best methods to study biofilms [37].

\section{Magnetic}

An interesting approach in static antibiofilm screening is the magnetic assay BioFilm Ring Test ${ }^{\bullet}$ for to evaluate the ability of bacteria to form biofilms. This assay consists on the immobilization measure in a modified 96 multiwell plate of magnetic beads attached with bacterial cells and have the ability of evaluates the bacterial biofilm formation without washing and staining steps $[38,39]$.

\section{Flow Antibiofilm Screening Assay}

Fluid dynamics is an important factor known to influence biofilm formation in natural environments. Have been observed that biofilms formed under high shear and turbulent flow is more strongly attached than their low-shear counterparts [40]. There is a need of developing new methods in which the testing of antibiofilm activity can be conducted under flow conditions. The requirements for these techniques include the possibility to predict the activity against the biofilm-associated organisms in vivo with reasonable reproducibility and low cost.

\section{Kadouri drip-fed biofilm system}

Useful for study the effect of compounds on the resident cells and inhibition, not to study biofilm-specific resistance, using a constant flow of culture medium can maintain bacterial growth for a long period and allows obtain lot of biomass that can be monitored by direct observation under inverted microscope useful for genomic and proteomic assays [41]. Kadouri biofilm system (Figure 1) have the ability of to study and characterize biofilms in reproducible way, and to emulate the different processes of biofilm formation, but although the system has the disadvantage of low pressure exert on microbial cells can be a bridge between static and flow antibiofilm assays $[41,42]$.

\section{Modified Robbins Device (MRD)}

Modified Robbins Device (MRD) (Figure 2) has been used to determine the biocidal activity against organisms attached in the biofilm from catheter segments [43]. Because provides a reproducible method of forming microbial biofilms. The MRD offers an ability of producing naturally occurring biofilms and maintaining their structural integrity for study [44]. The MRD allows the study of various flow biofilm models by different microorganisms, in different growth media and or on different substrata and is compatible with highthroughput screening methods. Because to discs with biofilms formed can be transferred for biocidal antibiofilm testing in a microplate, giving the opportunity for that different products and/or protocols can be tested at the same time [45].

\section{Tubular Capillary Electrochromatography (CEC)}

Capillary electrochromatography (CEC) is a capillary

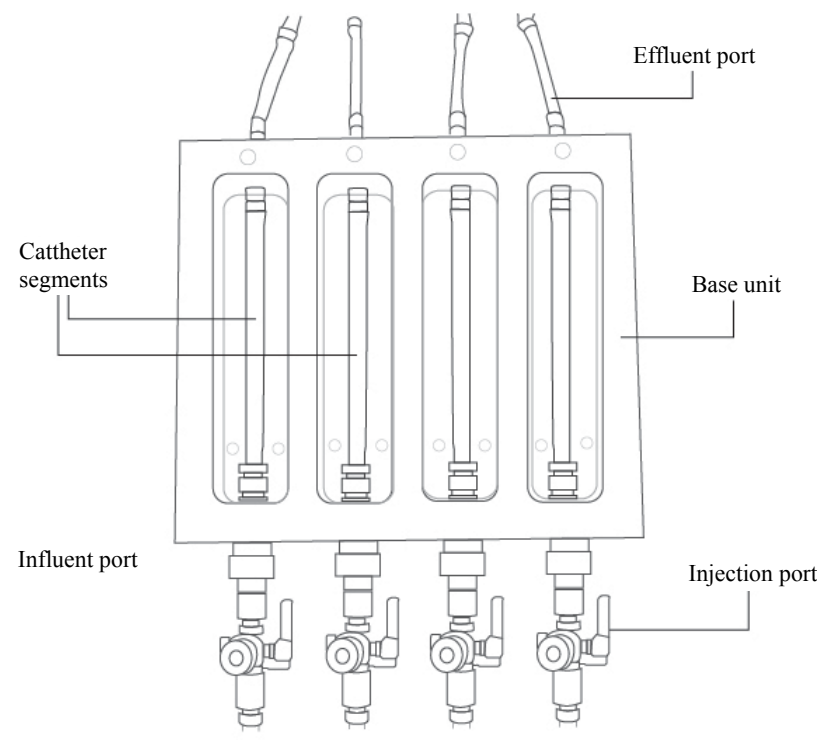

Figure 1: Kadouri biofilm system for flow biofilm study.

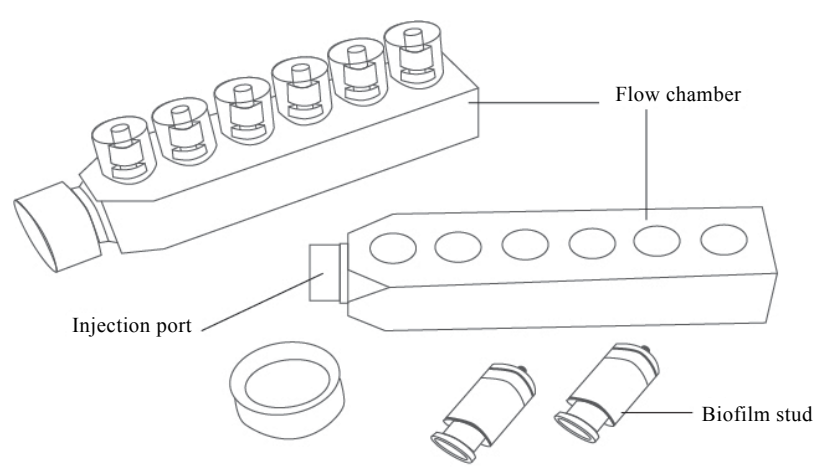

Figure 2: Modified Robbins Device (MRD) used to determine the biocidal activity against organisms attached in different surface materials. 


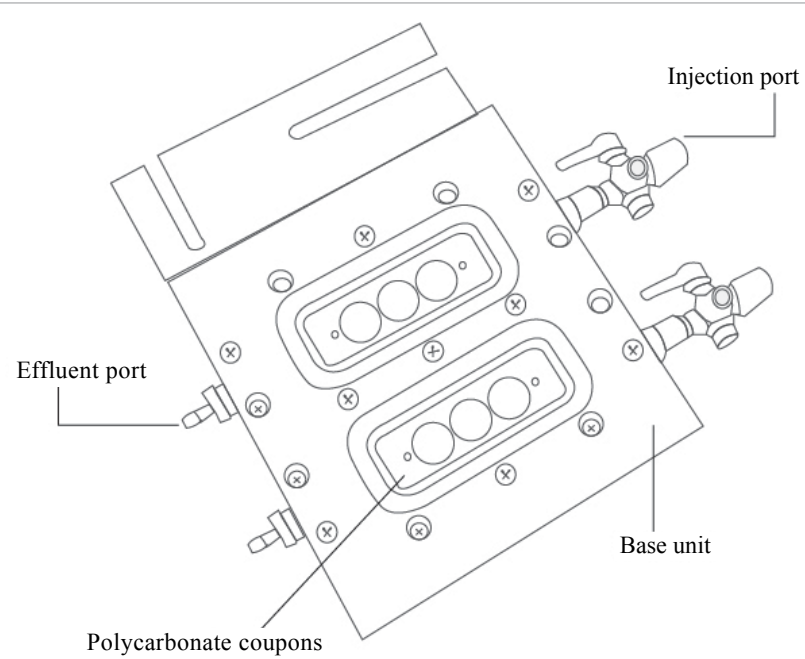

Figure 3: FC270 flow-cell system, device for flow biofilm study in compartments.

electromigration technique used in biofilm research. In CEC, electro osmotic flow induces the biofilm movement in a capillary as mobile phase, and further filled by a stationary phase. The retention of analytes is due to a combination of electrophoretic migration and chromatographic retention. Some authors have shown that CEC technique is successful applied to the separation, identification, and characterization of mixtures of both living and dead bacteria contained in biofilm structure, very useful in biofilm metabolomics research [46].

\section{Microcalorimetric assay}

Isothermal microcalorimetry (IMC) is used to study bacterial activity and bacterial growth in various types of samples ranging from soil to liquid cultures. Microcalorimetry measures the heat production of biological processes that is related with chemical and physical processes occurring in the organisms studied. Microbial activity may be quantified by the detection of heat output accompanying all biochemical redox reactions and can be used for measurements of metabolism of aerobic or anaerobic bacteria. Thus, IMC is very useful to give quantitative data about biofilm formation as well as metabolic status $[47,48]$. The major advantage of this technique is the rapid sample handling because further processing for sample preparation is not needed. The easy ability and the utility of this technique for biocide evaluation of antibiofilm activity have been demonstrated both static and flow biofilms [49]. In addition, calorimetry can be combined with other methods as microfluidics for provide more information on the biochemicals alterations under antibiotic exposure [50].

\section{FC270 flow-cell system}

FC270 flow-cell system (Figure 3) is a device for flow biofilm study that contains two compartments, with polycarbonate coupons. Within the device, bacterial growth media is perfused in a surface on which bacteria are adhered, providing both a large growing surface and an observation area. The FC270 system is particularly useful for the analysis of resulting biofilms using confocal laser scanning microscopy (CLSM). In addition, the FC270 system has the advantage to study biofilm formation in different materials and surfaces [51]. However, there are three major limitations, as they are, a limited visualization the biofilm formation during development, only two biofilms can be studied per experiment, and require a large volume of growth medium in each experiment [17].

\section{Biofilm biosensor}

A biosensor is an electronic device with the ability to quantify biochemical and physiological changes in biological processes. Biosensors use transducers that convert a signal in one form of energy to another form of energy that can be measured and analyzed, depending on the type of energy; the transducer can be electrochemical, optical, acoustic and electronic. Using these devices is possible to detect different analytes between microbes within biofilm. The major advantages of biosensing system are its specificity, sensitivity, experimental reproducibility, as well as ability to analyte detection in optically opaque solutions, also the application both for the study of static and flow biofilms [51-53].

An interesting approach develops an innovative biofilm screening platform using dielectric microsensors for continuous growth assessment of Candida albicans and Pichia pastoris in different concentrations of antimicrobial drugs. Contactless dielectric microsensors have a high degree of sensitivity toward morphology changes, and can be integrated in a microfluidic device, give the ability to biofilm analysis platform, simultaneously provides quantitative results associated with multiple phenotypic changes in a cell population, that can be used for to study interactions between biofilm and antimicrobial $[54,55]$.

\section{Microfluidics}

Microfluidic devices manipulate fluids constrained to a small environment, in sub-millimeter scale. They provide closed system where bacterial biofilms can interact with hydrodynamic environments [56]. Microfluidic systems are compatible with integration of microfabricated sensors, creating automatable lab-on-a-chip platforms. For study flow biofilms, BioFlux ${ }^{\mathrm{TM}}$ device permits rapid measurement the fluorescence of flow biofilms with a plate reader, which permits initial high-throughput screening of their viability. BioFlux1000 apparatus is composed of an epifluorescence microscope, a pneumatic compressor, a camera, and 24-well or 48-well plates with microfluidic channels (Figure 4), for sterile media and effluent, permits assessing biofilm formation in a continuous, non- invasive manner and obtain unprecedented comparison of biofilm development by bacterial strains containing different mutations, but have the disadvantage of the

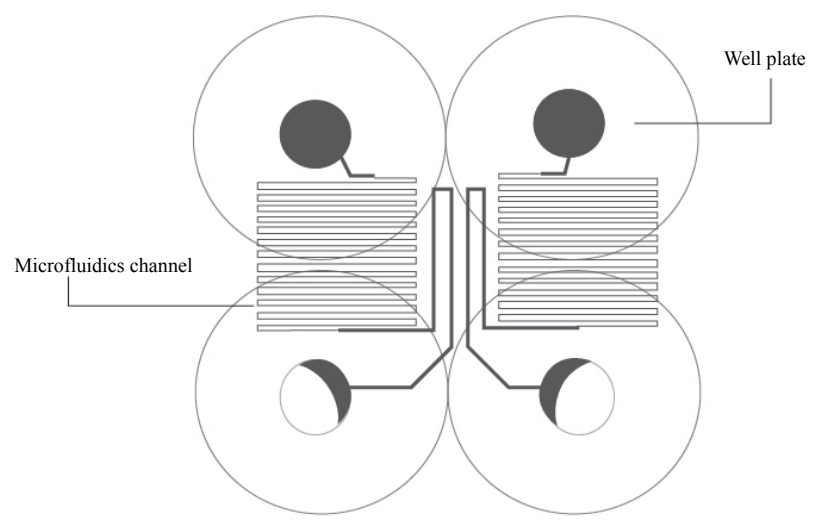

Figure 4: BioFlux ${ }^{\mathrm{TM}}$ device, plates with microfluidic channels, for sterile media and effluents. 
inability to collect effluent for analysis of metabolic products generated during biofilm growth [57-59].

For study biofilms have been developed other microfluidic device that integrates compartments for cell culture, oxygen gradient generator and an optical sensor. This microfluidic system is a useful in biofilm studies where oxygen consumption measures are required in microaerobic and anaerobic conditions [60].

\section{Genetic Biofilm Screening Model}

These methods are very useful for quantification of biofilm from environmental samples and static or flow systems and allow study polimicrobial biofilms attached to different surfaces [27].

\section{Real Time Quantitative-Reverse Transcription- PCR (qRT- PCR)}

qRT-PCR has been proposed as a promising indicator of cell viability because can detects all cells in a sample, including the dead cells and has been applied to quantify a specific microorganism in biofilm [61], because is very useful to determine the number of RNA transcripts from bacterial biofilms. qRT-PCR have the advantage to be highly sensitive, and can be used to quantify gene expression from small amount of biofilm samples. SYBR Green and dual-labeled probe (Taqman) are the most frequently used qRT-PCR methods and can to discriminate and count both live and dead cells in a microbiological sample $[62,63]$.

\section{Fluorescence in situ hybridization FISH}

The multiplex fluorescence in situ hybridization (M-FISH) is a method that use fluorescent labeled oligonucleotide probes specific $16 \mathrm{~S}$ rRNA sequences and have allowed in situ analysis of the spatial and temporal dynamics of different bacterial populations within oral biofilms. The advantages of using M-FISH to spatially discriminate between various members of the microbial community involve the ability for identification of uncultured bacteria and the rapid manufacturing of new oligonucleotide probes, the combined use of M-FISH with CLSM monitors permits obtain three-dimensional spatial distribution of different bacteria in multispecies biofilms and can quantify semi planktonic biofilms in their natural habitat [64]. FISH is a genetic alternative because can be applied to environmental and clinical samples, some authors have showed that FISH limitations can be solved with peptide nucleic acid (PNA) probes that using synthetic DNA analogues with stronger binding to DNA/RNA, and present higher specificity and sensitivity than conventional DNA probes [65].

\section{Whole Animal Biofilm Models}

The soil nematode Caenorhabditis elegans is a versatile host that has been used extensively for the study of various pathogens. Is a bioassay compatible with high-throughput screening technologies, and a have the advantage to detect toxic compounds that affect nematode viability, using the vital dye SYTOX for measure worm survival in presence of pathogenic microorganisms $[66,67]$.

C. elegans has shown to be an interesting infectious model in the research of host parasite interactions and evaluate the participation of different genes in virulence and immunity. An important factor of the C. elegans pathogenicity models is the similarity between mammalian pathogenesis by Gram-positive bacteria and the infectious process in $C$. elegans. Likewise, biofilm formation is an important virulence factor in C. elegans infection models for obstructing the pharynx nematode [68].
Also, C. albicans have the ability to colonize the intestine of nematodes forming biofilm and kills the worms by forming an intricate network of pseudohyphae that penetrate through their cuticle. This filamentation has shown to be important in fungal biofilm formation and virulence $[69,66]$.

Furthemore, one interesting approach is to evaluate compounds that interfere with bacterial quorum sensing. In this way an inhibitor of quorum sensing present in the bacteria Chromobacterium violaceum protected C. elegans from bacterial killing. This confirms the use of $C$. elegans infectious model for screening of new quorum sensing blockers $[70,71]$.

Equally, Galleria mellonela larvae have shown to be an interesting model in antifungal quorum sensing inhibitors model [72]. Because $G$. mellonella model have an innate immune system based in hemocytes that mimic fungal-pathogens interactions [73].

\section{Functional Biofilm Model}

Inhibitors targeting various mechanisms of biofilm formation have been analyzed. And is an important strategy in inhibition of the mechanisms by which microorganisms interact with each other within biofilm, in that way screening platforms that evaluate microbial social evolution can help identify novel therapeutic targets and assist in the rational design of therapies that avoid selection for resistance [74].

\section{Quorum sensing}

Gram negative bacteria such as Vibrio fischeri communicate by the production, distribution and detection of a class of small- molecules known as $\mathrm{N}$-acyl-homoserine lactones (AHL). In terms of the communication mechanism, 3-oxohexanoyl- L -homoserine- lactone (OHHL) is free to diffuse in and out of cells and is detected by the LuxR receptor protein. At this point, the LuxR-OHHL complex activates gene transcription, useful in bioluminescence methods. This mode of AHL-mediated quorum sensing is prevalent amongst numerous Gram negative bacteria [74].

Several quorum sensing blocking strategies are directed to looking for inhibition of the synthase enzyme responsible for the production of the signaling molecule or receptor protein; inhibition of the chemical signal mediated by OHHL; or inhibition of the receptor protein that modulates quorum sensing [75,76]. In this way enzyme and receptorcoupled high-throughput cell-free screen have been developed for find inhibitors of intercellular quorum-sensing signals as quorum sensing inhibitors approach [77].

\section{Antibiofilm detachment activity}

Traditionally, laboratory experiments focus on the attachment of planktonic batch-cultured or chemostat cultured cells to surfaces and the subsequent biofilm growth. The detachment and dispersal of cells from biofilms has received less attention. Detachment can be produced by increase of fluid pressure or by endogenous enzymatic degradation, as well as the release of EPS or surface-binding proteins. Detachment is evaluated normally in biofilm removal strategies, but biofilm dispersion is a process involved in colonization of new reservoirs [78]. Fluorescence microscopy and scanning electron microscopy (SEM), have been used for to evaluate the chemical removal of biofilm [79-81] Equally, was developed a microtitre plate biofilm detachment assay with safranin staining [22,23]. An important molecular target is degradation of the matrix that results in the detachment of cells from the colony and their release into the environment, regulated by accessory gene regulatory (agr) system, producing matrix-degrading gene products 
implicated in active biofilm dispersal as proteases, deoxyribonucleases, and surfactants [82].

\section{Checkerboard assay}

Because microbes within a biofilm are up to a 1,000-fold more resistant to antibiotics and are inherently insensitive to the host immune response, microorganisms in a biofilm represent a significant hurdle for antibiotic treatment. For that reason is necessary to determinate synergistic action of antimicrobial agents for biofilm elimination [83]. Checkerboard assay is a common technique to test antimicrobial combinations, even if it does not always reliably show additive effects when agents are combined and can be revealed with colorimetric and fluorometric dyes. Using the broth microdilution checkerboard method, synergistic interactions are frequently seen using the following formula for obtain Fractional Inhibitory Concentration $(\mathrm{FIC})$ index: $\mathrm{FIC}=(\mathrm{Ac} / \mathrm{Aa})+(\mathrm{Bc} / \mathrm{Ba})$, where $\mathrm{Ac}$ and $\mathrm{Bc}$ are the minimum inhibitory concentration (MICs) of compounds in combination, and $\mathrm{Aa}$ and $\mathrm{Ba}$ are the MICs of drugs $\mathrm{A}$ and $\mathrm{B}$ alone [84]. Synergism by the checkerboard method is defined as a Fractional Inhibitory Concentration (FIC) index of $\leq 0.5$, additive effect is defined as an FIC index of $>0.5$ and $\leq 1$, Indifference effect is defined as an FIC index of $>1$ and $\leq 2$ and antagonism effect is defined as an FIC index of $>4$. Concentrations within the FIC panel were such that the MIC of each antibiotic was in the middle of the range of concentrations tested [85]

\section{In vitro wound biofilm model}

Biofilm can be present in wounds, and cause the majority of nonhealing wounds, increasing the global cost of chronic wounds and mortality and morbidity in patients affected. Biofilm is related with failures in epithelialization and granulation tissue formation, and promotes a low-grade inflammatory response that interferes with wound healing, so that is important develop techniques that evaluate antibiofilm wound management [86]. The colony-drip flow reactor (DFR) was implemented for to evaluate in vitro biofilms in a way that simulates the chronic wound environment $[87,88]$. Equally, constant depth film fermenter (CDFF) has been used in the formation of multiple biofilms from wounds. An important feature of this system is the possibility of variation of key parameters, as are nutrient source, temperature, oxygen availability and substrata. Also allows study various aspects of biofilm physiology in presence of antimicrobial therapies and biocides as are chlorhexidine, sodium hypochlorite, tetracycline and silver [89].

\section{Bioluminiscence}

Bioluminescence Imaging (BLI) is a reproducible, robust and automatable method to analyze in vivo infectious diseases models and quantitatively monitor infection and microbial load in an in vivo model. BLI is based on the detection of visible light (photons) that is produced by an enzymatic oxidation of a substrate, catalyzed by luciferase enzymes. It is one of the few imaging methods that can non-invasively quantify cell viability [90]. Other alternative protocol is the Adenosine Triphosphate (ATP) bioluminescence method, which measure the action of the nucleotide ATP in the energy exchange of biological processes. ATP is present in all metabolically active cells, which is released when cells are lysed, and can be measured by bioluminescence using luciferin-luciferase reaction, has been utilized for to quantify viable bacteria in biofilm formation [91].

Also, Staphylococcus aureus and Pseudomona aeruginosa, were made bioluminescent by insertion of a lux operon. The bioluminescent signals produced for these bacteria can be used for both in vitro studies and the development of an in vivo model, allowing assessment in real time of the physiological state of the biofilms [92].

\section{Confocal Laser Scanning Microscopy (CLSM)}

The observation of microbial cells and biological changes is important to give exact information on antimicrobial action within functional biofilm structure. This is done by digital image processing and tridimensional biofilm structures can thus be scanned and then reconstructed and quantified after data processing using dedicated software [93]. This approach allows multichannel imaging of cellular and extracellular constituents. In addition sample mounting allows many options for examination of bioaggregates and biofilms, although these techniques allow high-resolution imaging, the sample has to adapt to the technical requirements [94]. But the constant development and the use of fluorescent markers able to target specific constituents of the biofilm as matrix components, nucleic acid, and protein residues can to identify specific cellular physiological states and give the possibility to obtain information about of architecture, composition, and cellular organization of biofilm. Equally, the development of a high-throughput CLSM method, based on the use of a microtiter plate compatible with high- resolution imaging, offer the opportunity to amplify data, in biocide activity within the biofilm of Pseudomona aeruginosa, Bacillus subtilis, and Staphylococcus epidermidis because allowed observe biocides function in different patterns of fluorescence loss $[95,96]$.

\section{Conclusions}

It is important to develop and implement new diagnostics and assays to select appropriate antibiotics for the treatment of biofilm-associated disease [97]. Biofilms present challenging problems in prosthetic device infections and may contribute to other infections, including recurrent Pseudomonal pneumonia in cystic fibrosis patients and endocarditis. Because drug tolerance present in biofilms by quorum sensing circuits and adhesion makes it difficult to eradicate, in this order of ideas biofilm inhibitors discovery of these processes should also impact biofilm formation and infection spread [98].

The next antibiofilm technologies would be focused in the development of in vivo evaluation methods with the end to determine the action of new antimicrobial drugs or biocides against biofilm formation and can predict the clinical outcome in persistent infections of drug combinations or new treatment strategies, through application of specific pharmacokinetic and pharmacodynamic (PK/PD) parameters, that can be useful in establishing a successful anti-infective therapy. In addition, biosensor methods should be applied in new medical devices together to nanotechnological approach for to provide tools with the ability of detect and inhibit the biofilm in the early stages and thus to prevent nosocomial infections [99].

Finally, for implement antibiofilm drug discovery platform is necessary take account

1) selection species (fungus, bacteria),

2) incubation parameters (static or flow, aerobic or anaerobic), with the aim to obtain similar environmental and physical parameters presents in an in vivo biofilm,

3) specific aspects of biofilm formation, as time of biofilm maturation and biofilm mass development, and

4) selection of adequate method of detection and measure of 
Citation: Bueno J (2014) Anti-Biofilm Drug Susceptibility Testing Methods: Looking for New Strategies against Resistance Mechanism. J Microbial Biochem Technol S3: 004. doi:10.4172/1948-5948.S3-004

Page 7 of 9

the different species in the biofilms, depending of research topic (colorimetric, fluorometric, magnetic, genetic) [100].

\section{Acknowledgment}

The author acknowledges to Claudia Marcela Montes for the design of the figures contained in this review.

\section{References}

1. Lazar V (2011) Quorum sensing in biofilms--how to destroy the bacterial citadels or their cohesion/power? Anaerobe 17: 280-285.

2. Taraszkiewicz A, Fila G, Grinholc M, Nakonieczna J (2013) Innovative strategies to overcome biofilm resistance. Biomed Res Int 2013: 150653.

3. Simões M, Simões LC, Vieira MJ (2010) A review of current and emergent biofilm control strategies. LWT-Food Science and Technology 43: 573-583.

4. Chen L, Wen YM (2011) The role of bacterial biofilm in persistent infections and control strategies. Int J Oral Sci 3: 66-73.

5. Høiby N, Bjarnsholt T, Givskov M, Molin S, Ciofu O (2010) Antibiotic resistance of bacterial biofilms. Int J Antimicrob Agents 35: 322-332.

6. Tan SY, Chew SC, Tan SY2, Givskov M3, Yang L4 (2014) Emerging frontiers in detection and control of bacterial biofilms. Curr Opin Biotechnol 26: 1-6.

7. Poole K (2012) Bacterial stress responses as determinants of antimicrobia resistance. J Antimicrob Chemother 67: 2069-2089.

8. Epstein AK, Pokroy B, Seminara A, Aizenberg J (2011) Bacterial biofilm shows persistent resistance to liquid wetting and gas penetration. Proc Natl Acad Sci U S A 108: 995-1000

9. Soto SM (2013) Role of efflux pumps in the antibiotic resistance of bacteria embedded in a biofilm. Virulence 4: 223-229.

10. Dreszer C, Vrouwenvelder J, Paulitsch-Fuchs A, Zwijnenburg A, Kruithof J, et al. (2013) Hydraulic resistance of biofilms. Journal of Membrane Science 429: 436-447.

11. Fauvart M, De Groote VN, Michiels J (2011) Role of persister cells in chronic infections: clinical relevance and perspectives on anti-persister therapies. J Med Microbiol 60: 699-709.

12. Beceiro A, Tomás M, Bou G (2013) Antimicrobial resistance and virulence: a successful or deleterious association in the bacterial world? Clin Microbiol Rev 26: $185-230$

13. Ramage G, Rajendran R, Sherry L, Williams $C$ (2012) Fungal biofilm resistance. Int J Microbiol 2012: 528521.

14. Ammons MC (2010) Anti-biofilm strategies and the need for innovations in wound care. Recent Pat Antiinfect Drug Discov 5: 10-17.

15. Ranall MV, Butler MS, Blaskovich MA, Cooper MA (2012) Resolving biofilm infections: current therapy and drug discovery strategies. Curr Drug Targets 13: $1375-1385$

16. Merritt JH, Kadouri DE, O'Toole GA (2005) Growing and analyzing static biofilms. Curr Protoc Microbiol Chapter 1: Unit 1B.

17. Moormeier DE, Bayles KW (2014) Examination of Staphylococcus epidermidis biofilms using flow-cell technology. Methods Mol Biol 1106: 143-155.

18. Hengzhuang W, Høiby N, Ciofu O (2014) Pharmacokinetics and pharmacodynamics of antibiotics in biofilm infections of Pseudomonas aeruginosa in vitro and in vivo. Methods Mol Biol 1147: 239-254.

19. Kwasny SM, Opperman TJ (2010) Static biofilm cultures of Gram-positive pathogens grown in a microtiter format used for anti-biofilm drug discovery. Curr Protoc Pharmacol Chapter 13: Unit 13A.

20. Peeters E, Nelis HJ, Coenye T (2008) Comparison of multiple methods for quantification of microbial biofilms grown in microtiter plates. $\mathrm{J}$ Microbiol Methods 72: 157-165

21. Peng F, Hoek EM, Damoiseaux R (2010) High-content screening for biofilm assays. J Biomol Screen 15: 748-754.

22. Chaignon P, Sadovskaya I, Ragunah Ch, Ramasubbu N, Kaplan JB, et al. (2007) Susceptibility of staphylococcal biofilms to enzymatic treatments depends on their chemical composition. Appl Microbiol Biotechnol 75: 125-132.

23. Lembke C, Podbielski A, Hidalgo-Grass C, Jonas L, Hanski E, et al. (2006)
Characterization of biofilm formation by clinically relevant serotypes of group A streptococci. Appl Environ Microbiol 72: 2864-2875

24. Zodrow KR, Schiffman JD, Elimelech M (2012) Biodegradable polymer (PLGA) coatings featuring cinnamaldehyde and carvacrol mitigate biofilm formation. Langmuir 28: 13993-13999.

25. Welch K, Cai Y, Strømme M (2012) A method for quantitative determination of biofilm viability. Journal of Functional Biomaterials 3: 418-431.

26. Cady NC, McKean KA, Behnke J, Kubec R, Mosier AP, et al. (2012) Inhibition of biofilm formation, quorum sensing and infection in Pseudomonas aeruginosa by natural products-inspired organosulfur compounds. PLoS One 7: e38492.

27. Pantanella F, Valenti P, Natalizi T, Passeri D, Berlutti F (2013) Analytica techniques to study microbial biofilm on abiotic surfaces: pros and cons of the main techniques currently in use. Ann Ig 25: 31-42.

28. Syre H, Phyu S, Sandven P, Bjorvatn B, Grewal HM (2003) Rapid colorimetric method for testing susceptibility of Mycobacterium tuberculosis to isoniazid and rifampin in liquid cultures. J Clin Microbiol 41: 5173-5177.

29. Pratten J, Ready D (2010) Use of biofilm model systems to study antimicrobial susceptibility. Methods Mol Biol 642: 203-215.

30. Girard LP, Ceri H, Gibb AP, Olson M, Sepandj F (2010) MIC versus MBEC to determine the antibiotic sensitivity of Staphylococcus aureus in peritoneal dialysis peritonitis. Perit Dial Int 30: 652-656.

31. Harding M, Howard R, Daniels G, Mobbs S, Lisowski S et al. (2011) A multi-well plate method for rapid growth, characterization and biocide sensitivity testing of microbial biofilms on various surface materials. In Science against microbial pathogens: communicating current research and technological advances, Formatex : 872-877.

32. Burton E, Yakandawala N, LoVetri K, Madhyastha MS (2007) A microplate spectrofluorometric assay for bacterial biofilms. J Ind Microbiol Biotechnol 34 $1-4$.

33. Rampersad SN (2012) Multiple applications of Alamar Blue as an indicator of metabolic function and cellular health in cell viability bioassays. Sensors (Basel) 12: 12347-12360

34. Sandberg ME, Schellmann D, Brunhofer G, Erker T, Busygin I, et al. (2009) Pros and cons of using resazurin staining for quantification of viable Staphylococcus aureus biofilms in a screening assay. J Microbiol Methods 78: 104-106.

35. Francolini I, Norris P, Piozzi A, Donelli G, Stoodley P (2004) Usnic acid, a natural antimicrobial agent able to inhibit bacterial biofilm formation on polymer surfaces. Antimicrob Agents Chemother 48: 4360-4365.

36. Smith K, Hunter IS (2008) Efficacy of common hospital biocides with biofilms of multi-drug resistant clinical isolates. J Med Microbiol 57: 966-973.

37. Netuschil L, Auschill TM, Sculean A, Arweiler NB (2014) Confusion over live/ dead stainings for the detection of vital microorganisms in oral biofilms--which stain is suitable? BMC Oral Health 14: 2.

38. Chavant P, Gaillard-Martinie B, Talon R, Hébraud M, Bernardi T (2007) A new device for rapid evaluation of biofilm formation potential by bacteria. $\mathrm{J}$ Microbio Methods 68: 605-612.

39. Badel S, Laroche C, Gardarin C, Bernardi T, Michaud P (2008) New method showing the influence of matrix components in Leuconostoc mesenteroides biofilm formation. Appl Biochem Biotechnol 151: 364-370.

40. Purevdorj B, Costerton JW, Stoodley P (2002) Influence of hydrodynamics and cell signaling on the structure and behavior of Pseudomonas aeruginosa biofilms. Appl Environ Microbiol 68: 4457-4464.

41. Jurgens DJ, Sattar SA, Mah TF (2008) Chloraminated drinking water does not generate bacterial resistance to antibiotics in Pseudomonas aeruginosa biofilms. Lett Appl Microbiol 46: 562-567.

42. Simões LC, Lemos M, Araújo P, Pereira AM, Simões M (2011) The effects of glutaraldehyde on the control of single and dual biofilms of Bacillus cereus and Pseudomonas fluorescens. Biofouling 27: 337-346.

43. Raad I, Hanna H, Dvorak T, Chaiban G, Hachem R (2007) Optimal antimicrobial catheter lock solution, using different combinations of minocycline, EDTA, and 25-percent ethanol, rapidly eradicates organisms embedded in biofilm. Antimicrob Agents Chemother 51: 78-83.

44. Whiteley M, Brown E, McLean RJ (1997) An inexpensive chemostat apparatus for the study of microbial biofilms. Journal of microbiological methods 30: 125-132. 
Citation: Bueno J (2014) Anti-Biofilm Drug Susceptibility Testing Methods: Looking for New Strategies against Resistance Mechanism. J Microbial Biochem Technol S3: 004. doi:10.4172/1948-5948.S3-004

Page 8 of 9

45. Coenye T, De Prijck K, De Wever B, Nelis HJ (2008) Use of the modified Robbins device to study the in vitro biofilm removal efficacy of NitrAdine, a novel disinfecting formula for the maintenance of oral medical devices. J App Microbiol 105: 733-740.

46. Chen J, Fallarero A, Määttänen A, Sandberg M, Peltonen J, et al. (2008) Living cells of Staphylococcus aureus immobilized onto the capillary surface in electrochromatography: a tool for screening of biofilms. Anal Chem 80: 51035109.

47. Astasov-Frauenhoffer M, Braissant O, Hauser-Gerspach I, Daniels AU, Weiger $\mathrm{R}$, et al. (2012) Isothermal microcalorimetry provides new insights into biofilm variability and dynamics. FEMS Microbiol Lett 337: 31-37.

48. Braissant O, Bonkat G, Wirz D, Bachmann A (2013) Microbial growth and isothermal microcalorimetry: growth models and their application to microcalorimetric data. Thermochimica Acta 555: 64-71.

49. Braissant O, Wirz D, Göpfert B, Daniels AU (2010) Use of isothermal microcalorimetry to monitor microbial activities. FEMS Microbiol Lett 303: 1-8.

50. Buchholz F, Wolf A, Lerchner J, Mertens F, Harms H, et al. (2010) Chip calorimetry for fast and reliable evaluation of bactericidal and bacteriostatic treatments of biofilms. Antimicrob Agents Chemother 54: 312-319.

51. Rzhepishevska O, Hakobyan S, Ruhal R, Gautrot J, Barbero D et al. (2013) The surface charge of anti-bacterial coatings alters motility and biofilm architecture. Biomaterials Science 1: 589-602.

52. D'Souza SF (2001) Microbial biosensors. Biosens Bioelectron 16: 337-353.

53. Su L, Jia W, Hou C, Lei Y (2011) Microbial biosensors: a review. Biosens Bioelectron 26: 1788-1799.

54. Gottschamel J, Richter L, Mak A, Jungreuthmayer C, Birnbaumer G, et al (2009) Development of a disposable microfluidic biochip for multiparameter cell population measurements. Anal Chem 81: 8503-8512.

55. Ertl P, Heer R (2009) Interdigitated impedance sensors for analysis of biological cells in microfluidic biochips. e \& i Elektrotechnik und Informationstechnik 126 : 47-50.

56. Kim J, Park HD, Chung S (2012) Microfluidic approaches to bacterial biofilm formation. Molecules 17: 9818-9834

57. Benoit MR, Conant CG, lonescu-Zanetti C, Schwartz M, Matin A (2010) New device for high-throughput viability screening of flow biofilms. Appl Environ Microbiol 76: 4136-4142.

58. Nance WC, Dowd SE, Samarian D, Chludzinski J, Delli J, et al. (2013) A highthroughput microfluidic dental plaque biofilm system to visualize and quantify the effect of antimicrobials. J Antimicrob Chemother 68: 2550-2560.

59. Meyer MT, Roy V, Bentley WE, Ghodssi R (2011) Development and validation of a microfluidic reactor for biofilm monitoring via optical methods. Journal of Micromechanics and Microengineering 21: 054023.

60. Skolimowski M, Nielsen MW, Emnéus J, Molin S, Taboryski R, et al. (2010) Microfluidic dissolved oxygen gradient generator biochip as a useful tool in bacterial biofilm studies. Lab Chip 10: 2162-2169.

61. Li B, Chen JQ (2012) Real-time PCR methodology for selective detection of viable Escherichia coli $\mathrm{O} 157: \mathrm{H} 7$ cells by targeting Z3276 as a genetic marker. Appl Environ Microbiol 78: 5297-5304.

62. Pérez-Osorio AC, Franklin MJ (2008) qRT-PCR of Microbial Biofilms. CSH Protoc 2008: pdb.

63. Alvarez G, González M, Isabal S, Blanc V, León R (2013) Method to quantify live and dead cells in multi-species oral biofilm by real-time PCR with propidium monoazide. AMB Express 3: 1 .

64. Karygianni L, Hellwig E, Al-Ahmad A (2014) Multiplex fluorescence in situ hybridization (M-FISH) and confocal laser scanning microscopy (CLSM) to analyze multispecies oral biofilms. Methods Mol Biol 1147: 65-72.

65. Almeida C, Azevedo NF, Santos S, Keevil CW, Vieira MJ (2011) Discriminating multi-species populations in biofilms with peptide nucleic acid fluorescence in situ hybridization (PNA FISH). PLoS One 6: e14786.

66. Okoli I, Coleman JJ, Tampakakis E, An WF, Holson E, et al. (2009) Identification of antifungal compounds active against Candida albicans using an improved high-throughput Caenorhabditis elegans assay. PLoS One 4: e7025.

67. Moy TI, Conery AL, Larkins-Ford J, Wu G, Mazitschek R, et al. (2009) High- throughput screen for novel antimicrobials using a whole animal infection model. ACS Chem Biol 4: 527-533.

68. Begun J, Gaiani JM, Rohde H, Mack D, Calderwood SB, et al. (2007) Staphylococcal biofilm exopolysaccharide protects against Caenorhabditis elegans immune defenses. PLoS Pathog 3: e57.

69. Tampakakis E, Okoli I, Mylonakis E (2008) A C. elegans-based, whole animal in vivo screen for the identification of antifungal compounds. Nat Protoc 3 1925-1931.

70. Swem LR, Swem DL, O'Loughlin CT, Gatmaitan R, Zhao B, et al. (2009) A quorum-sensing antagonist targets both membrane-bound and cytoplasmic receptors and controls bacterial pathogenicity. Mol Cell 35: 143-153.

71. Ewbank JJ, Zugasti O (2011) C. elegans: model host and tool for antimicrobial drug discovery. Dis Model Mech 4: 300-304

72. Brackman G, Cos P, Maes L, Nelis HJ, Coenye T (2011) Quorum sensing inhibitors increase the susceptibility of bacterial biofilms to antibiotics in vitro and in vivo. Antimicrob Agents Chemother 55: 2655-2661.

73. Junqueira JC (2012) Galleria mellonella as a model host for human pathogens: recent studies and new perspectives. Virulence 3: 474-476.

74. Boyle KE, Heilmann S, van Ditmarsch D, Xavier JB (2013) Exploiting social evolution in biofilms. Curr Opin Microbiol 16: 207-212.

75. Lowery CA, Salzameda NT, Sawada D, Kaufmann GF, Janda KD (2010) Medicinal chemistry as a conduit for the modulation of quorum sensing. J Med Chem 53: 7467-7489.

76. Marsden DM, Nicholson RL, Skindersoe ME, Galloway WR, Sore HF, et al (2010) Discovery of a quorum sensing modulator pharmacophore by 3D smallmolecule microarray screening. Org Biomol Chem 8: 5313-5323.

77. Christensen QH, Grove TL, Booker SJ, Greenberg EP (2013) A high-throughput screen for quorum-sensing inhibitors that target acyl-homoserine lactone synthases. Proc Natl Acad Sci U S A 110: 13815-13820.

78. Hall-Stoodley L, Costerton JW, Stoodley P (2004) Bacterial biofilms: from the natural environment to infectious diseases. Nat Rev Microbiol 2: 95-108.

79. Johansen C, Falholt P, Gram L (1997) Enzymatic removal and disinfection of bacterial biofilms. Appl Environ Microbiol 63: 3724-3728.

80. Wood TK, Hong SH, Ma Q (2011) Engineering biofilm formation and dispersal. Trends Biotechnol 29: 87-94.

81. Wu JA, Kusuma C, Mond JJ, Kokai-Kun JF (2003) Lysostaphin disrupts Staphylococcus aureus and Staphylococcus epidermidis biofilms on artificia surfaces. Antimicrob Agents Chemother 47: 3407-3414

82. Boles BR, Horswill AR (2011) Staphylococcal biofilm disassembly. Trends Microbiol 19: 449-455.

83. Rogers SA, Huigens RW 3rd, Cavanagh J, Melander C (2010) Synergistic effects between conventional antibiotics and 2-aminoimidazole-derived antibiofilm agents. Antimicrob Agents Chemother 54: 2112-2118.

84. Mataraci E, Dosler S (2012) In vitro activities of antibiotics and antimicrobia cationic peptides alone and in combination against methicillin-resistan Staphylococcus aureus biofilms. Antimicrob Agents Chemother 56: 6366-6371.

85. Tin S, Sakharkar KR, Lim CS, Sakharkar MK (2009) Activity of Chitosans in combination with antibiotics in Pseudomonas aeruginosa. Int J Biol Sci 5: 153160

86. Metcalf DG, Bowler PG (2013) Biofilm delays wound healing: A review of the evidence. Burns and Trauma 1: 5 .

87. Woods J, Boegli L, Kirker KR, Agostinho AM, Durch AM, et al. (2012 Development and application of a polymicrobial, in vitro, wound biofilm model. J Appl Microbiol 112: 998-1006.

88. Lipp C, Kirker K, Agostinho A, James G, Stewart P (2010) Testing wound dressings using an in vitro wound model. J Wound Care 19: 220-226.

89. Hill KE, Malic S, McKee R, Rennison T, Harding KG et al. (2010) An in vitro model of chronic wound biofilms to test wound dressings and assess antimicrobial susceptibilities. J Antimicrob Chemother 65: 1195-1206.

90. Vande Velde G, Kucharíková S, Schrevens S, Himmelreich U, Van Dijck $P$ (2014) Towards non-invasive monitoring of pathogen-host interactions during Candida albicans biofilm formation using in vivo bioluminescence. Cell Microbiol 16: 115-130. 
Citation: Bueno J (2014) Anti-Biofilm Drug Susceptibility Testing Methods: Looking for New Strategies against Resistance Mechanism. J Microbial Biochem Technol S3: 004. doi:10.4172/1948-5948.S3-004

Page 9 of 9

91. Sánchez MC Llama-Palacios A Marín MJ, Figuero E, León R, et al. (2013) Validation of ATP bioluminescence as a tool to assess antimicrobial effects of mouthrinses in an in vitro subgingival-biofilm model. Med Oral Patol Oral Cir Bucal 18: e86-92.

92. Kadurugamuwa JL, Sin L, Albert E, Yu J, Francis K, et al. (2003) Direct continuous method for monitoring biofilm infection in a mouse model. Infect Immun 71: 882-890.

93. Kuehn M, Hausner M, Bungartz HJ, Wagner M, Wilderer PA, et al. (1998) Automated confocal laser scanning microscopy and semiautomated image processing for analysis of biofilms. Appl Environ Microbiol 64: 4115-4127.

94. Neu TR, Lawrence JR (2014) Advanced techniques for in situ analysis of the biofilm matrix (structure, composition, dynamics) by means of laser scanning microscopy. Methods Mol Biol 1147: 43-64.

95. Bridier A, Briandet R (2014) Contribution of confocal laser scanning microscopy in deciphering biofilm tridimensional structure and reactivity. Methods Mol Biol 1147: $255-266$
96. Bridier A, Dubois-Brissonnet F, Greub G, Thomas V, Briandet R (2011) Dynamics of the action of biocides in Pseudomonas aeruginosa biofilms. Antimicrob Agents Chemother 55: 2648-2654.

97. Clatworthy AE, Pierson E, Hung DT (2007) Targeting virulence: a new paradigm for antimicrobial therapy. Nat Chem Biol 3: 541-548.

98. Barczak AK, Hung DT (2009) Productive steps toward an antimicrobial targeting virulence. Curr Opin Microbiol 12: 490-496.

99. Aruguete DM, Kim B, Hochella MF, Ma Y, Cheng Y, et al. (2013) Antimicrobia nanotechnology: its potential for the effective management of microbial drug resistance and implications for research needs in microbial nanotoxicology Environmental Science: Processes \& Impacts 15: 93-102.

100. Standar K, Kreikemeyer B, Redanz S, Münter WL, Laue M, et al. (2010) Setup of an in vitro test system for basic studies on biofilm behavior of mixed-species cultures with dental and periodontal pathogens. PLoS One 5.
This article was originally published in a special issue, Bacteria: Biochemical Physiology handled by Editor. Prof. Cheorl-Ho KIM, Sungkyunkwan University, Korea 